Check for updates

Cite this: RSC Adv., 2017, 7, 23255

Received 14th March 2017

Accepted 13th April 2017

DOI: $10.1039 / \mathrm{c} 7 \mathrm{ra03045b}$

rsc.li/rsc-advances

\section{Magnetic hollow carbon microspheres as a reusable adsorbent for rhodamine $B$ removal $\dagger$}

\author{
Feifei Lu, ${ }^{\text {b }}$ Ci Huang, ${ }^{a}$ Lijun You, (D) *a Jiabing Wang ${ }^{a}$ and Qiqing Zhang ${ }^{* a}$
}

Magnetic hollow carbon microspheres (MHCMs) were fabricated with a dual alternative constitution of cavities and porous carbon shells by a combination of microwave-assistant polycondensation and surfactant-free emulsion polymerization. The MHCM was characterized by transmission electron microscopy, X-ray diffraction, thermogravimetric analysis, vibrating sample magnetometry and $\mathrm{N}_{2}$ adsorption/desorption isotherms. The MHCMs possessed features of uniform morphologies, high surface area $\left(680 \mathrm{~m}^{2} \mathrm{~g}^{-1}\right)$, large pore volume $\left(0.61 \mathrm{~cm}^{3} \mathrm{~g}^{-1}\right)$ and magnetic responsiveness. The MHCMs were used as an adsorbent to remove rhodamine B (RB). The removal efficiency of RB reached $99.5 \%$ and the adsorption capacity of the MHCMs reached as high as $300 \mathrm{mg} \mathrm{g}^{-1}$. The adsorption process followed the Langmuir isotherm very well. The enthalpy change was $28.35 \mathrm{~kJ} \mathrm{~mol}^{-1}$. The negative free energy change indicated that the adsorption process was feasible and spontaneous. The positive entropy change showed that there was an increase in disorder in the adsorption system. The removal process was endothermic and interaction controlled. The adsorption kinetics fitted well with the pseudo-secondorder kinetics model. The removal efficiency of RB remained over $90 \%$ after six consecutive cycles, which demonstrated the high adsorption performance and favourable reusability of the MHCMs.

\section{Introduction}

Synthetic dyes with complex molecular structures are highly stable and difficult to undergo biodegradation in aqueous solutions. ${ }^{1,2}$ If these highly coloured and undesirable components are discharged in waterways without appropriate treatment, the reoxygenation capacity of the water could be damaged and the biological activity in the aquatic environment would be destroyed. ${ }^{3}$ Moreover, some of these dyes are toxic, mutagenic and carcinogenic in nature and may result in serious health problems to human. ${ }^{4}$ In recent years, the components of dyes in wastewater have become more and more intricate due to the increasing diversity of industrial products, ${ }^{5}$ which makes dyes removal one of the most difficult tasks. Rhodamine $B(R B)$, one of the most widely used dyes, is extensively used in the textile, leather, cosmetics, food and biomedical laboratories. ${ }^{6}$ It is harmful towards the skin, eyes and respiratory tract. It can also cause carcinogenicity, neurotoxicity and chronic toxicity to humans and animals. ${ }^{7}$ Therefore, it is of significant practical

${ }^{a}$ Institute of Biomedical and Pharmaceutical Technology, Fuzhou University, Fuzhou 350002, China. E-mail: yljyoyo@126.com

${ }^{b}$ Institute of Food Safety and Environment Monitoring, Fuzhou University, Fuzhou, 350108, China.E-mail: zhangqiq@126.com

$\dagger$ Electronic supplementary information (ESI) available: Fig. S1 pseudo-first-order kinetic plots of RB removal by MHCM; Fig. S2 pseudo-second-order kinetic plots of RB removal by MHCM; Fig. S3 the plot of lnk vs. 1/T. See DOI: 10.1039/c7ra03045b importance to ensure the complete removal of RB from aqueous solutions to protect human health and the environment.

Methods for processing dyes in aqueous solution involve physical, chemical and biological approaches. Techniques such as adsorption, flocculation, chemical oxidation, electrolysis, and biological treatments have been extensively applied in dye wastewater treatment. ${ }^{8-11}$ Among these techniques, the adsorption process is regarded as an attractive alternative, especially when the adsorbent is inexpensive and readily available. $^{12,13}$ Many adsorbents, such as activated carbon, peat, clay, silica, algae, fungi, etc., have been investigated to remove dyes in aqueous solutions. ${ }^{\mathbf{1 4 - 1 7}}$ Nevertheless, most of them possess limitations, such as hazardous by-products, high cost or intensive energy requirements. Moreover, it is difficult to remove many dyes from effluents, because many dyes are not easily degradable and are generally not removed from wastewater by conventional wastewater systems. ${ }^{18,19}$

Porous activated carbon materials are highly appealing because of their controllable pore architecture, high surface area, large pore volume and specific physical and chemical properties. ${ }^{20-22}$ These features contribute to their excellent performance as adsorbents. The adsorption capability of dyes onto porous carbon surfaces depends on the type of pore texture of the adsorbent and on the interactions between the adsorbent and the adsorbate. ${ }^{21-23}$ In spite of their already distinctive advantages, the improvement of porous carbon has been continuously acquired for specific applications. Many porous carbons have been successfully prepared through templating methods using mesoporous silica, zeolites and 
polymer microspheres as hard templates, or using copolymer surfactants as soft templates. ${ }^{24-26}$ Nevertheless, the preparation processes by these templating approaches are usually complicated, tedious and cost and/or time-consuming, which limit their practical applications..$^{\mathbf{2 0 2 4}}$ Moreover, a slow adsorption rate or separation inconvenience are other challenges preventing them from wider application in water treatment. ${ }^{27}$ Thus, porous carbon materials with properties of a fast adsorption rate and facile separation have become more and more attractive. In this work, magnetic $\mathrm{Fe}_{3} \mathrm{O}_{4}$ nanoclusters were incorporated to make porous carbon microspheres with a facile magnetic separation property. ${ }^{13}$ A porous multilayers structure was designed to provide the adsorbent with an enhanced high surface area, large pore volume and specific mechanical and chemical properties. Thus, the design of the magnetic porous carbon microsphere should be able to achieve the purpose of developing an adsorbent with the desired characteristics of superior adsorption capability, a fast adsorption rate and facile separation.

Herein, we developed a combination approach of microwaveassistant polycondensation and surfactant-free emulsion polymerization to fabricate porous magnetic carbon microspheres (MHCMs) consisting of an $\mathrm{Fe}_{3} \mathrm{O}_{4}$ core and porous carbon shells. The designed structure provided distinctive characteristics, including a high surface area, large pore volume, appropriate pore sizes and magnetic responsiveness. Phenol-formaldehyde (PF) resin was used as the carbon source to afford a high carbonforming yield. Polystyrene (PS) was used as the template to form hollow cavities. In addition, the alternative constitution of PS and PF layers provided a controllable approach to develop the structure of multiple porous carbon shells and isolated inner space. The BET surface area of the MHCM was determined to be $680 \mathrm{~m}^{2} \mathrm{~g}^{-1}$ with a total pore volume of $0.61 \mathrm{~cm}^{3} \mathrm{~g}^{-1}$. The MHCM microspheres showed an enhanced high capacity for RB removal in aqueous solutions. The effects of the dosage of MHCM, the contact time, temperature, initial $\mathrm{pH}$ and initial $\mathrm{RB}$ concentration on the adsorption of RB were studied. The thermodynamics and kinetics of the adsorption process were investigated. After six consecutive cycles, the removal efficiency of RB still retained over $90 \%$, indicating that the MHCM is a favourable reusable adsorbent.

\section{Experimental section}

\subsection{Materials}

Phenol, aqueous ammonia solution (25\%), ferric chloride hexahydrate $\left(\mathrm{FeCl}_{3} \cdot 6 \mathrm{H}_{2} \mathrm{O}\right)$, sodium acetate (NaOAc), ethylene glycol, anhydrous ethanol, trisodium citrate dehydrate $\left(\mathrm{Na}_{3} \mathrm{Cit}\right)$, aqueous formaldehyde solution (37\%) and cetyltrimethyl ammonium bromide were purchased from Shanghai Chemical Reagents Company. Potassium persulfate (KPS) and cetyltrimethylammonium bromide were purchased from Shanghai Aijian Reagent Company. Deionized water was used in all the experiments.

\subsection{Preparation of the $\mathrm{Fe}_{3} \mathrm{O}_{4} / \mathrm{PS} / \mathrm{PF}$ microspheres}

The $\mathrm{Fe}_{3} \mathrm{O}_{4} /$ polystyrene $\left(\mathrm{Fe}_{3} \mathrm{O}_{4} / \mathrm{PS}\right)$ composite microspheres were synthesized using surfactant-free seeded emulsion polymerization with $\mathrm{Fe}_{3} \mathrm{O}_{4}$ magnetite colloidal nanocrystal clusters as the seeds, as reported in our earlier work. ${ }^{28}$ Preparation of $\mathrm{Fe}_{3} \mathrm{O}_{4} / \mathrm{PS} /$ phenol-formaldehyde-resin $\left(\mathrm{Fe}_{3} \mathrm{O}_{4} / \mathrm{PS} / \mathrm{PF}\right)$ microspheres was realized through a microwave-assistant hydrothermal method. ${ }^{29}$ The coating of a phenol-formaldehyde-resin (PF) shell on the $\mathrm{Fe}_{3} \mathrm{O}_{4} / \mathrm{PS}$ microspheres was carried out in a CEM Discover microwave machine using the single mode and continuous power at $2.45 \mathrm{GHz}$. In a typical experiment, $50 \mathrm{mg}$ phenol, $2 \mathrm{mg}$ cetyl trimethyl ammonium bromide, $0.15 \mathrm{~mL}$ ammonia aqueous solution and $30 \mathrm{~mL}$ deionized water were mixed to form a mixture. Then, $10 \mathrm{mg} \mathrm{Fe} \mathrm{O}_{4} / \mathrm{PS}$ microspheres was added into the mixture, which was then treated by ultrasonication for $5 \mathrm{~min}$ to obtain a homogenous dispersion. Then, $0.2 \mathrm{~mL}$ formaldehyde solution was injected into the dispersion. Subsequently, the dispersion was transferred into a microwave reaction vessel and placed in the vessel holder. The reaction was started at $160^{\circ} \mathrm{C}$ and lasted for $30 \mathrm{~min}$. After the reaction was completed, the asprepared $\mathrm{Fe}_{3} \mathrm{O}_{4} / \mathrm{PS} / \mathrm{PF}$ microspheres were collected by magnetic separation, washed with deionized water and ethanol three times and finally dried in vacuum at $45{ }^{\circ} \mathrm{C}$ for $4 \mathrm{~h}$.

\subsection{Fabrication of the $\mathrm{Fe}_{3} \mathrm{O}_{4} / \mathrm{PS} / \mathrm{PF} / \mathrm{PS} / \mathrm{PF}$ microspheres}

First, the $\mathrm{Fe}_{3} \mathrm{O}_{4} / \mathrm{PS} / \mathrm{PF} /$ polystyrene $\left(\mathrm{Fe}_{3} \mathrm{O}_{4} / \mathrm{PS} / \mathrm{PF} / \mathrm{PS}\right)$ microspheres were synthesized as follows: $100 \mathrm{mg}$ of the $\mathrm{Fe}_{3} \mathrm{O}_{4} / \mathrm{PS} / \mathrm{PF}$ spheres was dispersed in $125 \mathrm{~mL}$ deionized water and stirred to form a homogeneous medium, and then $\mathrm{N}_{2}$ was bubbled through for $30 \mathrm{~min}$. After the injection of $4.5 \mathrm{~mL}$ styrene, the temperature was raised to $73{ }^{\circ} \mathrm{C}$ and the reaction was initiated by adding $8 \mathrm{~mL}$ KPS solution $\left(10 \mathrm{mg} \mathrm{mL}^{-1}\right)$ and lasted for $6 \mathrm{~h}$. The obtained $\mathrm{Fe}_{3} \mathrm{O}_{4} / \mathrm{PS} / \mathrm{PF} / \mathrm{PS}$ product was collected by magnetic separation and washed with deionized water and ethanol, respectively. The $\mathrm{Fe}_{3} \mathrm{O}_{4} / \mathrm{PS} / \mathrm{PF} / \mathrm{PS} /$ phenol-formaldehyde-resin $\left(\mathrm{Fe}_{3} \mathrm{O}_{4} / \mathrm{PS} / \mathrm{PF} / \mathrm{PS} / \mathrm{PF}\right)$ microspheres were fabricated by coating $\mathrm{PF}$ shells on $\mathrm{Fe}_{3} \mathrm{O}_{4} / \mathrm{PS} / \mathrm{PF} / \mathrm{PS}$ microspheres using the microwave-assistant hydrothermal method. Specificity, $10 \mathrm{mg}$ $\mathrm{Fe}_{3} \mathrm{O}_{4} / \mathrm{PS} / \mathrm{PF} / \mathrm{PS}$ microspheres was added in to a solution containing $40 \mathrm{mg}$ phenol, $2 \mathrm{mg}$ cetyl trimethyl ammonium bromide and $0.15 \mathrm{~mL}$ ammonia aqueous solution. The mixture was treated by ultrasonication for $2 \mathrm{~min}$ to obtain a homogenous dispersion. Then, $0.2 \mathrm{~mL}$ formaldehyde was added and the reaction was carried on at $160{ }^{\circ} \mathrm{C}$ for $30 \mathrm{~min}$. The as-prepared $\mathrm{Fe}_{3} \mathrm{O}_{4} / \mathrm{PS} / \mathrm{PF} / \mathrm{PS} / \mathrm{PF}$ microspheres were collected by a magnet and dried in vacuum at $45^{\circ} \mathrm{C}$ for $4 \mathrm{~h}$.

\subsection{Preparation of the MHCMs}

The as-prepared $\mathrm{Fe}_{3} \mathrm{O}_{4} / \mathrm{PS} / \mathrm{PF} / \mathrm{PS} / \mathrm{PF}$ microspheres were carbonized at $650{ }^{\circ} \mathrm{C}$ under a nitrogen flow, and the carbonization process lasted for $2 \mathrm{~h}$. The formation of porous carbon shells and the elimination of the PS shell occurred synchronously during the carbonization process. The resulting carbon composites were washed with deionized water and ethanol, respectively, and collected by a magnet. Then, they were dried in vacuum at $45{ }^{\circ} \mathrm{C}$ for $4 \mathrm{~h}$ and the MHCM microspheres were obtained. Porous PF carbon was fabricated using the same method for comparison. 


\subsection{Characterization methods and instruments}

Transmission electron microscopy (TEM) images were taken on a JEM-2100F transmission electron microscope at an accelerating voltage of $200 \mathrm{kV}$. Fourier transform infrared spectra (FTIR) were determined on a NEXUS-470 FT-IR spectrometer and the spectra were scanned over the range of $400-4000 \mathrm{~cm}^{-1}$. All of the dried samples were mixed with $\mathrm{KBr}$ and then compressed to form pellets. Magnetic characterization was carried out with a vibrating sample magnetometer on a Model 6000 physical property measurement system (Quantum, USA) at $300 \mathrm{~K}$. Thermogravimetric analysis (TGA) measurements were performed on a Pyris 1 TGA instrument and taken under a constant flow of nitrogen of $40 \mathrm{~mL} \mathrm{~min}^{-1}$. The $\mathrm{N}_{2}$ adsorption/desorption isotherms was carried out using a surface area analyzer (Quanta Chrome Nova1200). The specific surface area was determined by Brunauer-Emmett-Teller equation (BET) and the total pore volume (VT) was defined as the maximum amount of nitrogen adsorbed at a relative pressure of $P / P_{0}=0.99$.

\subsection{Adsorption of RB by the MHCM microspheres}

Stock solutions were prepared by dissolving $\mathrm{RB}$ in deionized water to concentrations of $20 \mathrm{mg} \mathrm{L}^{-1}, 50 \mathrm{mg} \mathrm{L}^{-1}, 100 \mathrm{mg} \mathrm{L}^{-1}$, $150 \mathrm{mg} \mathrm{L^{-1 }}, 200 \mathrm{mg} \mathrm{L}^{-1}$ and $400 \mathrm{mg} \mathrm{L}^{-1}$, respectively. The amount of the MHCMs was fixed at $0.6 \mathrm{~g} \mathrm{~L}^{-1}$. Decolourization experiments were carried out in a constant temperature shaker. The concentration of RB was measured by a spectrophotometer at $554 \mathrm{~nm}$ (the maximum absorbency wavelength). The solution without the adsorbent served as the control.

The adsorption capacity $q_{\mathrm{e}}\left(\mathrm{mg} \mathrm{g}^{-1}\right)$ was determined from the following equation:

$$
q_{\mathrm{e}}=\frac{\left(C_{\mathrm{i}}-C_{\mathrm{e}}\right) \times V}{m}
$$

The removal efficiency of RB was calculated by the following equation:

$$
\text { Removal efficiency }=\frac{C_{\mathrm{i}}-C_{\mathrm{e}}}{C_{\mathrm{i}}} \times 100 \%
$$

where $C_{\mathrm{i}}$ is the initial concentration $\left(\mathrm{mg} \mathrm{L}^{-1}\right)$ of $\mathrm{RB}, C_{\mathrm{e}}$ is the final or equilibrium concentration $\left(\mathrm{mg} \mathrm{L}^{-1}\right)$ of $\mathrm{RB}, V$ is the total volume of the solution (L), $m$ is the dosage of MHCM (g) and $q_{\mathrm{e}}$ is the amount of RB adsorbed per unit weight of MHCM (mg $\left.\mathrm{g}^{-1}\right)$.

The effects of the initial pH, dosage of MHCM, initial dye concentration and adsorption time on the decolourization ability were studied. The $\mathrm{pH}$ in these experiments was the original $\mathrm{pH}$ of the dye solutions unless mentioned specifically.

\section{Results and discussion}

\subsection{Synthesis of the MHCMs}

The synthesis procedure of the MHCMs is presented in Scheme 1. The $\mathrm{Fe}_{3} \mathrm{O}_{4} / \mathrm{PS}$ microspheres were fabricated through a surfactant-free emulsion polymerization, as reported in our previous work. ${ }^{28}$ A PF shell was coated on the $\mathrm{Fe}_{3} \mathrm{O}_{4} / \mathrm{PS}$ via

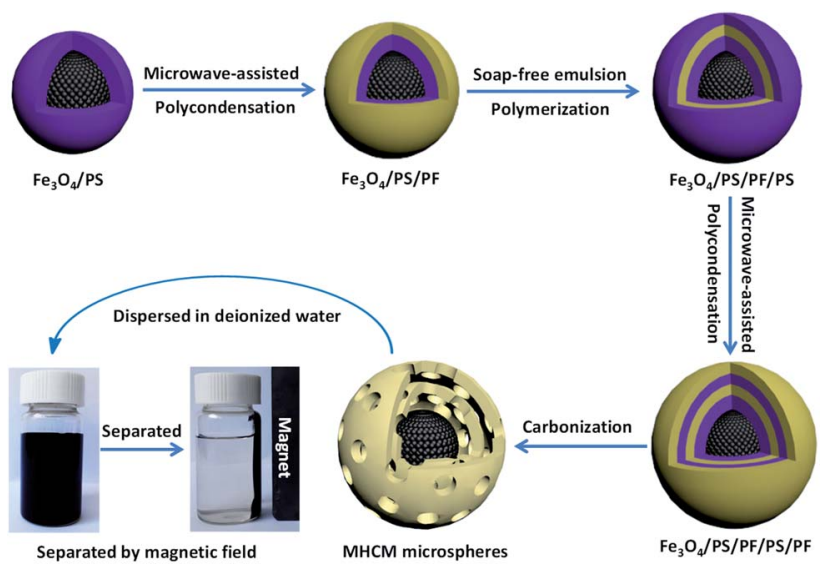

Scheme 1 Synthetic procedure of the MHCMs and their magnetic separation from aqueous solution.

a microwave-assisted condensation polymerization, resulting in double PS/PF shells. The $\mathrm{Fe}_{3} \mathrm{O}_{4} / \mathrm{PS} / \mathrm{PF}$ was coated by another PS shell through a surfactant-free seeded emulsion polymerization and $\mathrm{Fe}_{3} \mathrm{O}_{4} / \mathrm{PS} / \mathrm{PF} / \mathrm{PS}$ microspheres were obtained. Subsequently, the $\mathrm{Fe}_{3} \mathrm{O}_{4} / \mathrm{PS} / \mathrm{PF} / \mathrm{PS}$ microspheres were coated by a PF shell using a microwave-assisted approach and $\mathrm{Fe}_{3} \mathrm{O}_{4} / \mathrm{PS} / \mathrm{PF} / \mathrm{PS} / \mathrm{PF}$ microspheres with an alternate multilayer structure of PS and $\mathrm{PF}$ shells were formed. The as-fabricated $\mathrm{Fe}_{3} \mathrm{O}_{4} / \mathrm{PS} / \mathrm{PF} / \mathrm{PS} / \mathrm{PF}$ microspheres were carbonized at $650{ }^{\circ} \mathrm{C}$ under a nitrogen flow. In the carbonization process, the PS shells were eliminated and the PF layers become porous carbon shells by thermolysis. Thus, a hollow space was formed between the porous carbon shells and the magnetic $\mathrm{Fe}_{3} \mathrm{O}_{4}$ core.

The TEM images of the $\mathrm{Fe}_{3} \mathrm{O}_{4} / \mathrm{PS}$ microspheres are displayed in Fig. 1. It can be seen that the $\mathrm{Fe}_{3} \mathrm{O}_{4}$ nanoparticles were encapsulated by a PS shell with an average size of $580 \mathrm{~nm}$. The TEM images of the $\mathrm{Fe}_{3} \mathrm{O}_{4} / \mathrm{PS} / \mathrm{PF}, \mathrm{Fe}_{3} \mathrm{O}_{4} / \mathrm{PS} / \mathrm{PF} / \mathrm{PS}, \mathrm{Fe}_{3} \mathrm{O}_{4} / \mathrm{PS} / \mathrm{PF} /$ $\mathrm{PS} / \mathrm{PF}$ and MHCM composites microspheres are shown in Fig. 2. From the images, it could be found that all the microspheres were monodispersed, spherical in shape and uniform in size. The size of $\mathrm{Fe}_{3} \mathrm{O}_{4} / \mathrm{PS} / \mathrm{PF}, \mathrm{Fe}_{3} \mathrm{O}_{4} / \mathrm{PS} / \mathrm{PF} / \mathrm{PS}$ and $\mathrm{Fe}_{3} \mathrm{O}_{4} / \mathrm{PS} / \mathrm{PF} / \mathrm{PS} / \mathrm{PF}$ was $890 \mathrm{~nm}, 1092 \mathrm{~nm}$ and $1323 \mathrm{~nm}$, respectively. The increase in size proved the successful coating of the PF and PS shells. It could be clearly observed that the MHCM was of a multilayer

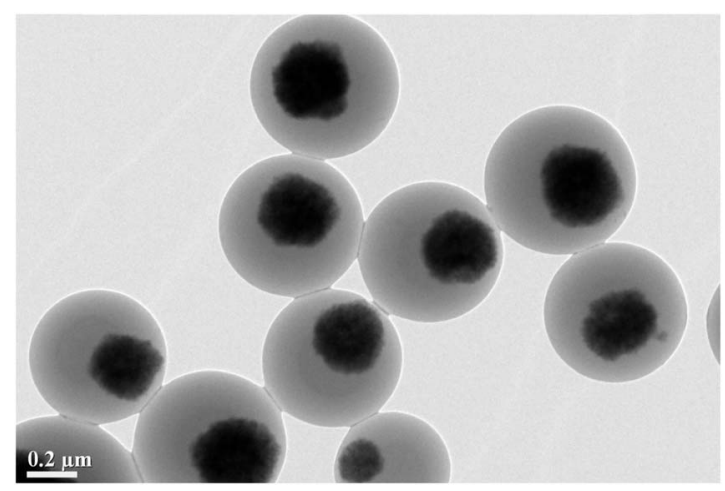

Fig. 1 TEM image of the $\mathrm{Fe}_{3} \mathrm{O}_{4} / \mathrm{PS}$ microspheres. 


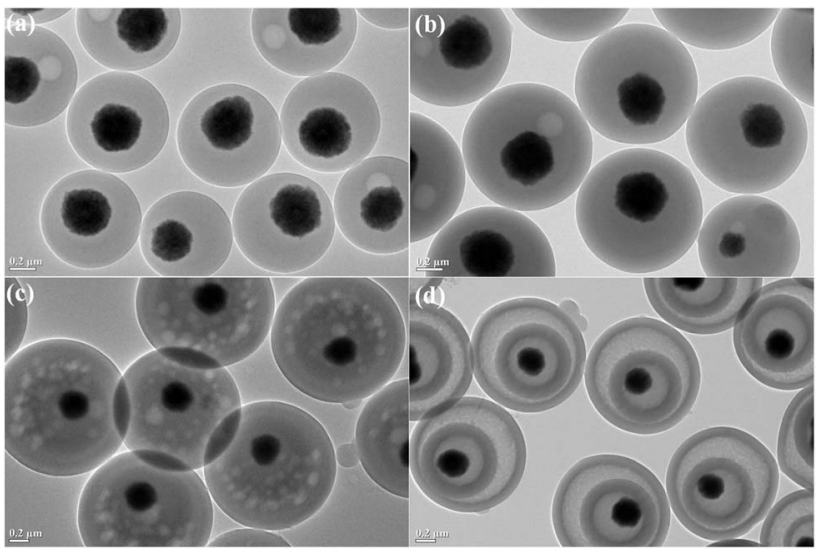

Fig. 2 TEM images of the (a) $\mathrm{Fe}_{3} \mathrm{O}_{4} / \mathrm{PS} / \mathrm{PF}$, (b) $\mathrm{Fe}_{3} \mathrm{O}_{4} / \mathrm{PS} / \mathrm{PF} / \mathrm{PS}$, (c) $\mathrm{Fe}_{3} \mathrm{O}_{4} / \mathrm{PS} / \mathrm{PF} / \mathrm{PS} / \mathrm{PF}$ and (d) MHCM microspheres.

hollow structure with a $\mathrm{Fe}_{3} \mathrm{O}_{4}$ core and alternating cavities and porous carbon shells. The size of the MHCM was $1180 \mathrm{~nm}$. Its inner carbon shell was $130 \mathrm{~nm}$ and the outer carbon shell was $100 \mathrm{~nm}$. The uniform core/shell structure and well-defined multilayer hollow structure of the microspheres indicated the microwave-assisted polycondensation for the PF coating, and showed that the approach to conversion of the product to hollow microspheres was facile and efficient for controlling the construction of a multilevel microstructure.

\subsection{Characterization of the MHCMs}

To confirm the coating of PF and PS shells, the samples $\mathrm{Fe}_{3} \mathrm{O}_{4}$, PF particles, $\mathrm{Fe}_{3} \mathrm{O}_{4} / \mathrm{PS}, \mathrm{Fe}_{3} \mathrm{O}_{4} / \mathrm{PS} / \mathrm{PF}, \mathrm{Fe}_{3} \mathrm{O}_{4} / \mathrm{PS} / \mathrm{PF} / \mathrm{PS}$ and $\mathrm{Fe}_{3} \mathrm{O}_{4} /$ $\mathrm{PS} / \mathrm{PF} / \mathrm{PS} / \mathrm{PF}$ were characterized by FT-IR spectroscopy (Fig. 3). The FT-IR spectroscopy results of the $\mathrm{Fe}_{3} \mathrm{O}_{4}$ nanoparticles and PF particles were characterized as the controls (Fig. 3I and II). It was observed that the $\mathrm{Fe}_{3} \mathrm{O}_{4} / \mathrm{PS}$ spectra (Fig. 3III) showed characteristic adsorption peaks in the ranges of 3009-3092 $\mathrm{cm}^{-1}$ and $1640-1495 \mathrm{~cm}^{-1}$, which were attributed to the $\mathrm{C}-\mathrm{H}$

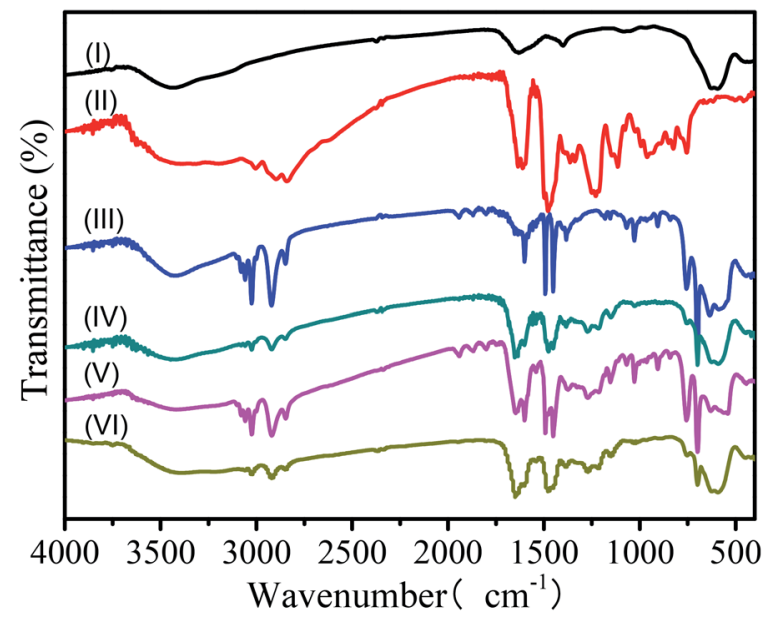

Fig. 3 FT-IR spectra of (I) $\mathrm{Fe}_{3} \mathrm{O}_{4}$ nanoparticles, (II) PF particles, (III) $\mathrm{Fe}_{3} \mathrm{O}_{4} / \mathrm{PS}$ microspheres, (IV) $\mathrm{Fe}_{3} \mathrm{O}_{4} / \mathrm{PS} / \mathrm{PF}$ microspheres, (V) $\mathrm{Fe}_{3} \mathrm{O}_{4} / \mathrm{PS}$ / $\mathrm{PF} / \mathrm{PS}$ and (VI) $\mathrm{Fe}_{3} \mathrm{O}_{4} / \mathrm{PS} / \mathrm{PF} / \mathrm{PS} / \mathrm{PF}$. bonds of the benzene ring. The stretching of the $\mathrm{C}-\mathrm{H}$ bonds of the saturated alkane from the PS shell could be identified at $2848 \mathrm{~cm}^{-1}$ and $2918 \mathrm{~cm}^{-1}$. The three adsorption peaks at 1600 , 1496 and $1447 \mathrm{~cm}^{-1}$ were due to the vibration of $\mathrm{C}-\mathrm{C}$ bonds in the benzene ring. The strong rocking modes of $\mathrm{CH}_{2}$ found at $757 \mathrm{~cm}^{-1}$ and $701 \mathrm{~cm}^{-1}$ were from the single substituted benzene ring. ${ }^{30,31}$ These indicated the existence of PS shells. Compared with the spectrum of $\mathrm{Fe}_{3} \mathrm{O}_{4}$ (Fig. 3I), the adsorption peak at $582 \mathrm{~cm}^{-1}$ was the characteristic absorption of $\mathrm{Fe}-\mathrm{O}$ bonds, which confirmed the presence of $\mathrm{Fe}_{3} \mathrm{O}_{4}$ nanoparticles. ${ }^{31}$ The FT-IR spectrum of $\mathrm{Fe}_{3} \mathrm{O}_{4} / \mathrm{PS} / \mathrm{PF}$ microspheres (Fig. 3IV) had additional characteristic absorption of phenolic $\mathrm{O}-\mathrm{H}$ at 1385 $\mathrm{cm}^{-1}$, and $\mathrm{C}-\mathrm{O}$ stretching at $1275 \mathrm{~cm}^{-1}$ and $1140 \mathrm{~cm}^{-1}$, which originated from the PF shells (compared with the spectrum of PF in Fig. 3II).$^{32}$ Compared with the spectra of $\mathrm{Fe}_{3} \mathrm{O}_{4} / \mathrm{PS} / \mathrm{PF}$, the characteristic peaks of PS shells were obviously enhanced in the spectra of $\mathrm{Fe}_{3} \mathrm{O}_{4} / \mathrm{PS} / \mathrm{PF} / \mathrm{PS}$ (Fig. 3V), thus this suggested that the PS shells were coated onto the $\mathrm{Fe}_{3} \mathrm{O}_{4} / \mathrm{PS} / \mathrm{PF}$ microspheres. The characteristic peaks of $\mathrm{Fe}_{3} \mathrm{O}_{4}$, PS and PF shells were found in the spectrum of the $\mathrm{Fe}_{3} \mathrm{O}_{4} / \mathrm{PS} / \mathrm{PF} / \mathrm{PS} / \mathrm{PF}$ microspheres (Fig. 3VI). Moreover, the characteristic absorption of PS shells was reduced, but the characteristic peak absorption of PF shells was enhanced, implying the formation of a second layer of PF shells. The results confirmed that $\mathrm{Fe}_{3} \mathrm{O}_{4}$, PS and $\mathrm{PF}$ are components of the $\mathrm{Fe}_{3} \mathrm{O}_{4} / \mathrm{PS} / \mathrm{PF} / \mathrm{PS} / \mathrm{PF}$ microspheres and suggested the formation of a multilayer structure.

The thermal stability and the composition of the $\mathrm{Fe}_{3} \mathrm{O}_{4}$ nanoparticles, $\mathrm{PF}, \mathrm{Fe}_{3} \mathrm{O}_{4} / \mathrm{PS}$ and $\mathrm{Fe}_{3} \mathrm{O}_{4} / \mathrm{PS} / \mathrm{PF} / \mathrm{PS} / \mathrm{PF}$ microspheres were characterized by TGA in a nitrogen atmosphere (Fig. 4). A 21\% weight loss for $\mathrm{Fe}_{3} \mathrm{O}_{4}$ nanoparticles was found due to the thermolysis of the citrate stabilizer on the nanoclusters (Fig. 4a). ${ }^{20}$ Fig. 4b shows that the PS was completely decomposed at $530{ }^{\circ} \mathrm{C}$. The TGA curve presents the existence of two thermal degradation ranges in pyrogenation of the $\mathrm{PF}$ particles (Fig. 4c), which can be explained by water removal during condensation and by the carbonization of PF. This was similar to the reported cases in the literature. ${ }^{29,32}$ Compared with the TGA curves of $\mathrm{Fe}_{3} \mathrm{O}_{4}$, PS and PF, the decomposing of the $\mathrm{Fe}_{3} \mathrm{O}_{4} / \mathrm{PS} / \mathrm{PF} / \mathrm{PS} / \mathrm{PF}$ microspheres included elimination of the PS shells and carbonization of the PF shells (Fig. 4d). A 3.7\%

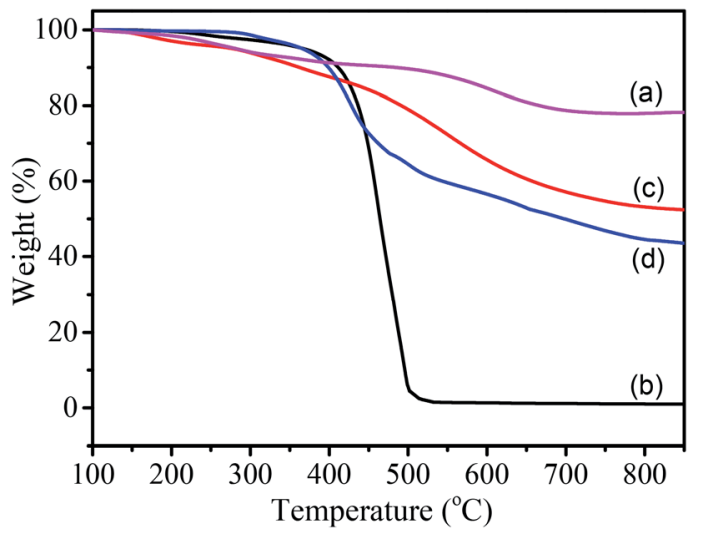

Fig. 4 TGA curves of (a) $\mathrm{Fe}_{3} \mathrm{O}_{4}$, (b) PS, (c) PF particles and (d) $\mathrm{Fe}_{3} \mathrm{O}_{4}$ / PS/PF/PS/PF microspheres. 


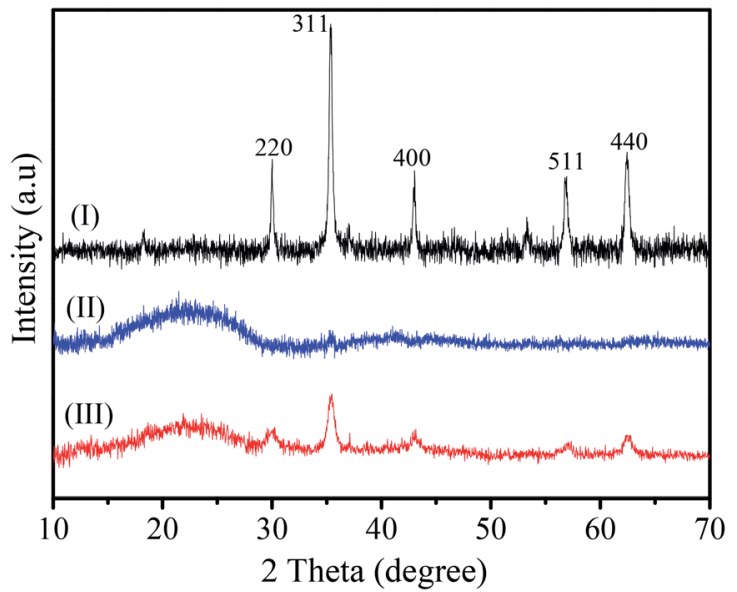

Fig. 5 XRD patterns of (I) $\mathrm{Fe}_{3} \mathrm{O}_{4}$ particles, (II) porous PF carbon nanospheres and (III) MHCMs.

weight loss occurred between $100{ }^{\circ} \mathrm{C}$ and $345^{\circ} \mathrm{C}$. This involved water condensation and volatilization of the unreacted oligomers. When the temperature rose from $345{ }^{\circ} \mathrm{C}$ to $669{ }^{\circ} \mathrm{C}$, a $49.2 \%$ weight loss occurred, this was caused by the elimination of various volatiles derivatives. ${ }^{28,29}$ This progress included thermal decomposition of the PS shells and carbonization of the PF shells. The third weight loss stage was above $669{ }^{\circ} \mathrm{C}$ due to continuing carbonization of the PF shells.

The crystalline structure of MHCMs was characterized by powder X-ray diffraction (XRD), as shown in Fig. 5. The $\mathrm{Fe}_{3} \mathrm{O}_{4}$ and porous $\mathrm{PF}$ carbon were applied as controls. It was obvious the typical diffraction peaks at 220, 311, 400, 511 and 440 of the $\mathrm{Fe}_{3} \mathrm{O}_{4}$ particles appeared in the XRD pattern of the MHCMs. This suggested that the crystalline structure of $\mathrm{Fe}_{3} \mathrm{O}_{4}$ particles was well retained under the whole fabrication process. In addition, a broad peak presented at $2 \theta=16-28^{\circ}$, which was derived from the amorphous phase of the PF carbon shells (compared with Fig. 5II). The above results confirmed that magnetic $\mathrm{Fe}_{3} \mathrm{O}_{4}$ particles were coated onto the carbon shells.

The magnetic hysteresis curves are shown in Fig. 6. The magnetic $\mathrm{Fe}_{3} \mathrm{O}_{4}$ clusters are a typical superparamagnetic

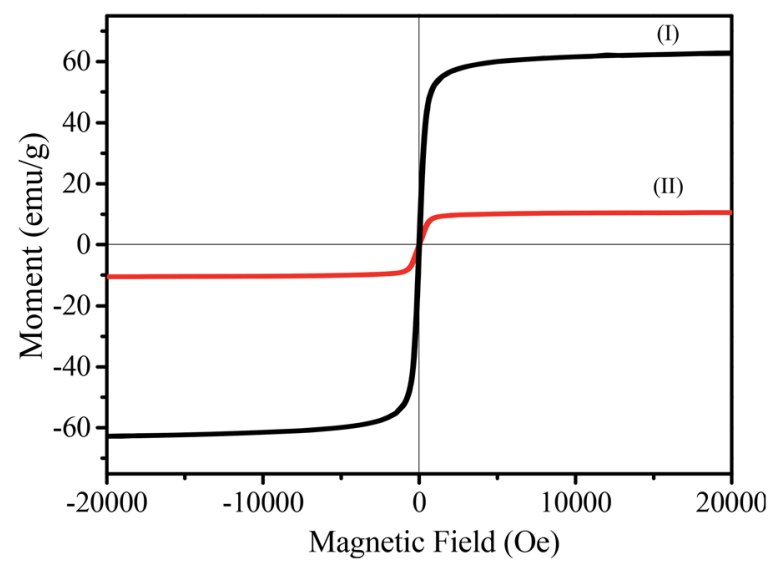

Fig. 6 Magnetic hysteresis curves of (I) magnetic $\mathrm{Fe}_{3} \mathrm{O}_{4}$ clusters; (II) MHCMs.

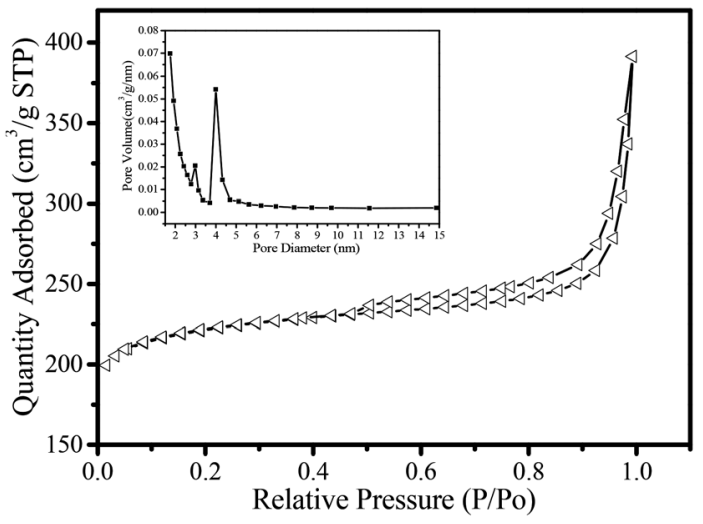

Fig. 7 Nitrogen adsorption/desorption isotherms of MHCM microspheres. The inserted was the pore-size distribution.

material and present a high saturation magnetization $\left(M_{\mathrm{s}}\right)$ of $62.9 \mathrm{emu}^{-1}$. As seen in Fig. 6II, the as-synthesized MHCM microspheres presented good superparamagnetic properties $\left(M_{\mathrm{s}}=10.3 \mathrm{emu}^{-1}\right)$. Compared with the magnetic hysteresis curve of $\mathrm{Fe}_{3} \mathrm{O}_{4}$, it showed that the MHCM was a superparamagnetic material. The MHCMs could rapidly respond to the magnetic field and could easily be separated from the aqueous solution within $1 \mathrm{~min}$ (Scheme 1).

Nitrogen adsorption/desorption isotherms of the MHCM carbon microspheres are shown in Fig. 7. The sorption isotherm plot of the MHCMs was a combination of types I and IV, corresponding to micro-mesoporous materials according to the IUPAC classification. This showed the existence of different pore sizes in the hybrid spheres. The steep increase and high adsorbed volume $\left(200 \mathrm{~cm}^{3} \mathrm{~g}^{-1}\right.$ ) at low relative pressure was related to the presence of micropores, which were formed during the carbonization. The BET surface area of the MHMCs was $680 \mathrm{~m}^{2} \mathrm{~g}^{-1}$. The adsorption average pore width was $3.5 \mathrm{~nm}$ and the single point adsorption total pore volume at $P / P_{0}=0.99$ was $0.61 \mathrm{~cm}^{3} \mathrm{~g}^{-1}$. The $t$-plot micropore volume was $0.31 \mathrm{~cm}^{3} \mathrm{~g}^{-1}$ and the Barrett-JoynerHalenda desorption cumulative volume of pores was $0.33 \mathrm{~cm}^{3}$ $\mathrm{g}^{-1}$. Moreover, the almost vertical tails near to $P / P_{0}=0.99$ suggested the presence of macroporosity generated by removal of the PS template and carbonization of the PF shells. The pore-size distribution was evaluated using the BJH model. The MHCMs possessed dual narrow mesoporous size distributions near $2.9 \mathrm{~nm}$ and $4.0 \mathrm{~nm}$, respectively (the inset in Fig. 7). The unique pore properties and multilayer hollow structure of the MHCMs can be expected to be advantageous for applications in adsorption, separation and bioenrichment.

\subsection{Removal of rhodamine $B(\mathrm{RB})$ in aqueous solution}

3.3.1 Effect of MHCM dosage on RB removal. The removal of $\mathrm{RB}$ by different dosages of MHCMs was studied. $\mathrm{Fe}_{3} \mathrm{O}_{4}$ nanoparticles and single-carbon-layer mesoporous carbon microspheres (SLCM) were studied as controls. The results (Fig. 8a) showed that the removal efficiency of RB increased sharply as the dosage of MHCMs increased, due to the increase in porous active bonding sites, and reached a peak value of $99.5 \%$ when the 

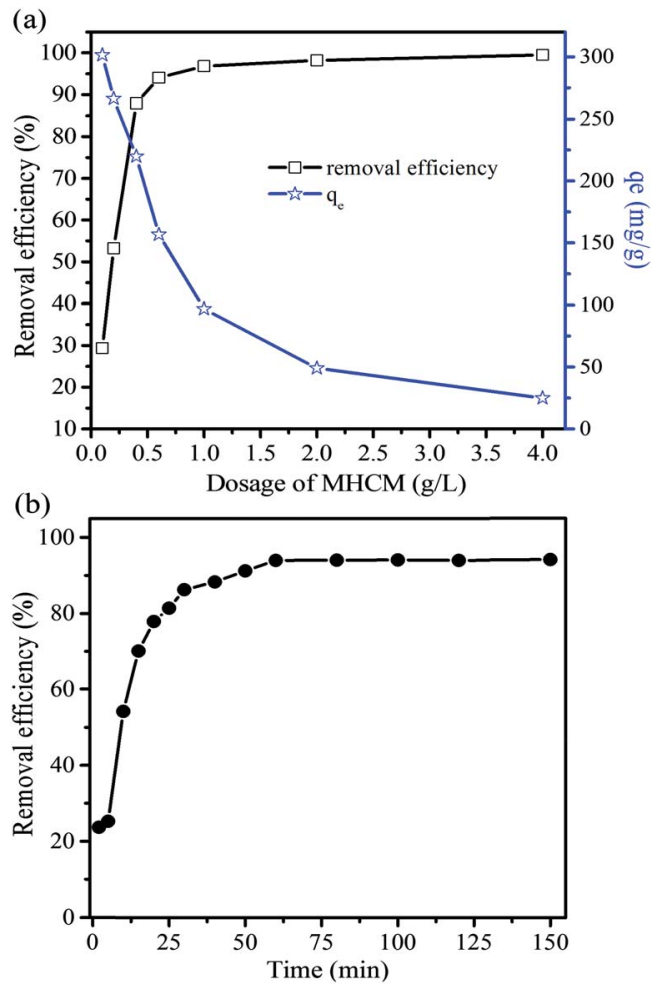

Fig. 8 (a) Effect of the dosage of MHCMs on the removal efficiency (RB concentration $100 \mathrm{mg} \mathrm{L}^{-1}$, temperature $25^{\circ} \mathrm{C}, \mathrm{pH}=7$ and adsorption time $120 \mathrm{~min}$ ); (b) effect of contact time on the decolourization efficiency ( $R B$ concentration $100 \mathrm{mg} \mathrm{L}^{-1}$, dosage of MHCMs $0.6 \mathrm{~g} \mathrm{~L}^{-1}, \mathrm{pH}=7$ and temperature $25^{\circ} \mathrm{C}$ ).

dosage was over $2.0 \mathrm{~g} \mathrm{~L}^{-1}$. The adsorption capacity $\left(q_{\mathrm{e}}\right)$ of the MHCMs reached as high as $300 \mathrm{mg} \mathrm{g}^{-1}$ when the dosage was $0.1 \mathrm{~g}$ $\mathrm{L}^{-1}$. It was found the $\mathrm{RB}$ could hardly be removed by $\mathrm{Fe}_{3} \mathrm{O}_{4}$ nanoparticles (Fig. S1 in the ESI $\dagger$ ). At the same condition, the single-carbon-layer mesoporous carbon microspheres (SLCMs), which possessed a BET surface area of $331.5 \mathrm{~m}^{2} \mathrm{~g}^{-1}$ and narrow mesoporous size distributions at $4.0 \mathrm{~nm}$ (Fig. S2†), removed 71\% of the $\mathrm{RB}$ with a dosage over $2.0 \mathrm{~g} \mathrm{~L}^{-1}$, albeit the removal efficiency was much lower than the MHCMs. Moreover, $q_{\mathrm{e}}$ of the SLCM was $177.4 \mathrm{mg} \mathrm{g}^{-1}$ when the dosage was $0.1 \mathrm{~g} \mathrm{~L}^{-1}$ (Fig. S3a $\dagger$ ), which was much lower than the MHCMs. The higher RB removal performance was caused by the larger BET surface area, unique pore properties and sandwich-like hollow structure (double porous carbon layers) of the MHCMs.

3.3.2 Effect of contact time on the removal efficiency. As the results show in Fig. 8b, the adsorption capacity initially increased with the increase in time and then kept at a constant value thereafter. More than $94 \%$ of the dye was removed within $60 \mathrm{~min}$ and the reaction reached equilibrium in $80 \mathrm{~min}$. According to the slope of the curve, the sample exhibited a fast removal rate for $\mathrm{RB}$ in the initial stage, and the removal of $\mathrm{RB}$ could reach $70 \%$ in the first $15 \mathrm{~min}$. When further prolonging the reaction time, the adsorption rate became obviously slower and equilibrium was reached in $80 \mathrm{~min}$. The rapid uptake of RB by MHCMs indicated a fast binding kinetics occurring in this process.
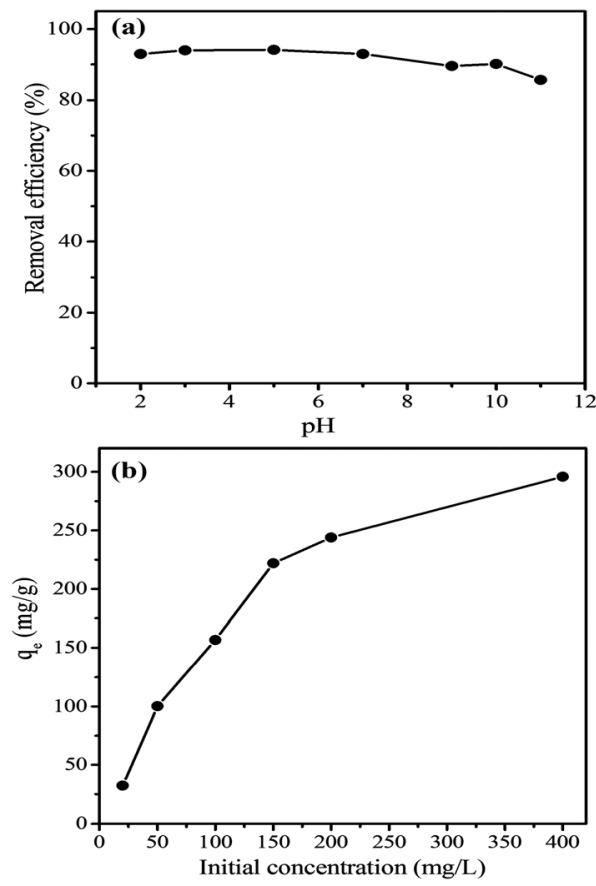

Fig. 9 (a) Effect of initial $\mathrm{pH}$ on the removal efficiency (RB concentration $100 \mathrm{mg} \mathrm{L}^{-1}$, dosage of MHCMs $0.6 \mathrm{~g} \mathrm{~L}^{-1}$, temperature $25^{\circ} \mathrm{C}$ and adsorption time $120 \mathrm{~min}$ ); (b) effect of the initial dye concentration (temperature $25^{\circ} \mathrm{C}$, adsorption time $120 \mathrm{~min}$, dosage of MHCMs $0.6 \mathrm{~g}$ $\mathrm{L}^{-1}, \mathrm{pH}=7$ ).

3.3.3 Effect of initial $\mathbf{p H}$ on the removal efficiency. Generally, the impact of $\mathrm{pH}$ is very important because it has tremendous effects on the surface properties of adsorbates and adsorbents. ${ }^{3,34}$ To investigate the effect of the initial $\mathrm{pH}$ on the removal of $\mathrm{RB}$, a series of experiments with different initial solution pHs in range of 2-11 was carried out. As shown in Fig. 9a, the MHCMs removed over $90.2 \%$ of $\mathrm{RB}$ at $\mathrm{pH} 2-10$ and $86 \%$ at $\mathrm{pH}=11$, which suggested that the MHCMs could remove organic dyes efficiently over a wide $\mathrm{pH}$ range. When the $\mathrm{pH}$ was over 8 , the removal efficiency slightly decreased as the pH increased, which may be caused by the existence of excess $\mathrm{OH}^{-}$ions competing with $\mathrm{RB}$ for the adsorption sites. The efficient elimination of $\mathrm{RB}$ over a wide $\mathrm{pH}$ range shows the MHCMs are beneficial for use in practical applications.

3.3.4 Effect of initial RB concentration. The adsorption capacity versus the initial $\mathrm{RB}$ concentration is presented in Fig. 9b. The SLCM was used to remove various initial concentrations of RB as comparisons. It was observed that an increase in the initial $\mathrm{RB}$ concentration led to an increase in the amount of RB adsorbed per unit weight of MHCM. A higher concentration resulted in a higher driving force of the concentration gradient. ${ }^{7,33}$ This driving force accelerated the diffusion of RB molecules from the solution into the adsorbent and decreased the resistance to the uptake of the RB. ${ }^{9}$ As the initial concentration increased from 20 to $400 \mathrm{mg} \mathrm{L}^{-1}$, the amounts of $\mathrm{RB}$ adsorbed on the adsorbent increased from 32.2 to $295.9 \mathrm{mg} \mathrm{g}^{-1}$. The same phenomenon was observed in the case of SLCM, but the amounts of RB adsorbed on the SLCM increased from 13.0 to $152.6 \mathrm{mg} \mathrm{g}^{-1}$ (Fig. S3b†), which was much lower than with the 
MHCMs. The results indicated that the design of double porous carbon layers and a sandwich-like hollow structure made the MHCMs possess enhanced high adsorption efficiency.

\subsection{Evaluation of adsorption isotherm models}

The adsorption isotherms of $\mathrm{RB}$ at various temperatures are shown in Fig. 10. The Langmuir, Freundlich and DubininRadushkevich isotherms were tested for the equilibrium description. $^{35,36}$ The Langmuir isotherm is represented by the following equation: ${ }^{37}$

$$
\frac{1}{q_{\mathrm{e}}}=\frac{1}{Q_{\mathrm{L}}}+\left(\frac{1}{Q_{\mathrm{L}} K_{\mathrm{L}}}\right) \frac{1}{C_{\mathrm{e}}}
$$

where $q_{\mathrm{e}}\left(\mathrm{mg} \mathrm{g}^{-1}\right)$ is the amount of RB adsorbed by per unit weight of MHCM, $C_{\mathrm{e}}\left(\mathrm{mg} \mathrm{L}^{-1}\right)$ is the equilibrium concentration of the $\mathrm{RB}, Q_{\mathrm{L}}\left(\mathrm{mg} \mathrm{L}^{-1}\right)$ is the maximum monolayer adsorption capability and $K_{\mathrm{L}}\left(\mathrm{L} \mathrm{mg}^{-1}\right)$ is a constant related to the free energy of adsorption.

The well-known Freundlich isotherm is often used for heterogeneous surface energy systems. ${ }^{38}$ The Freundlich equation is presented as:

$$
\ln q_{\mathrm{e}}=\ln K_{\mathrm{F}}+\frac{1}{n} \ln C_{\mathrm{e}}
$$

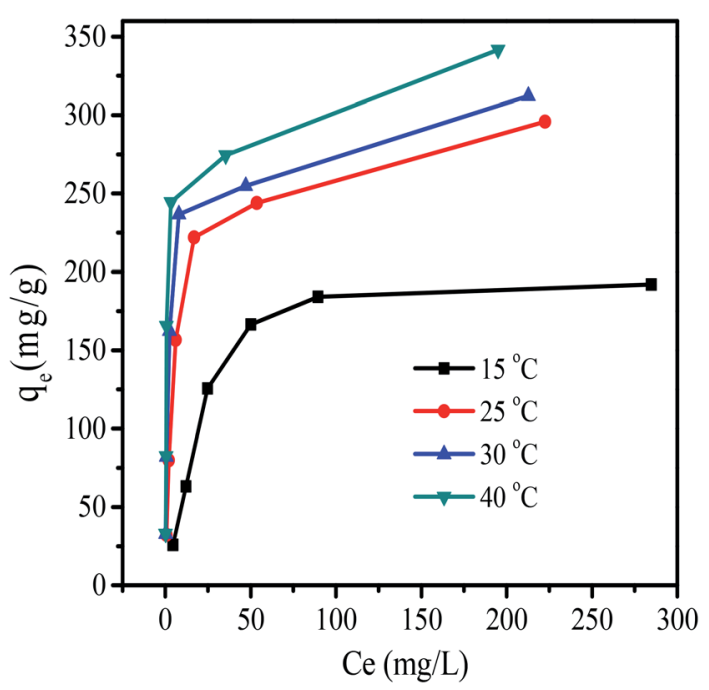

Fig. 10 Adsorption isotherms of $\mathrm{RB}$ at various temperatures by MHCMs (dosage of MHCMs $0.6 \mathrm{~g} \mathrm{~L}^{-1}, \mathrm{pH}=7$, adsorption time $120 \mathrm{~min}$, RB concentration $20,50,100,150,200$ and $400 \mathrm{mg} \mathrm{L}^{-1}$, respectively.).
The Dubinin-Radushkevich (D-R) isotherm is a more general isotherm because it does not assume a homogeneous surface or constant adsorption potential. ${ }^{39}$ The $\mathrm{D}-\mathrm{R}$ isotherm equation is as follows:

$$
\ln q_{\mathrm{e}}=\ln Q_{\mathrm{D}}-\beta \varepsilon^{2}
$$

where $\beta\left(\mathrm{mg}^{2} \mathrm{~kJ}^{-2}\right)$ is a constant related to the mean free energy of adsorption per mole of the adsorbate. $Q_{\mathrm{D}}\left(\mathrm{mg} \mathrm{g}^{-1}\right)$ is the theoretical saturation capacity and $\varepsilon$ is the Polanyi potential, which is equal to $\varepsilon=-R T \ln \left(1+1 / C_{\mathrm{e}}\right)$ where $R\left(R=8.314 \mathrm{~J} \mathrm{~mol}^{-1}\right.$ $\mathrm{K}^{-1}$ ) is the gas constant and $T(\mathrm{~K})$ is the absolute temperature.

The normalized standard deviation of $q_{\mathrm{e}}\left(\Delta q_{\mathrm{e}}\right)$ derived from each isotherm is calculated as:

$$
\Delta q_{\mathrm{e}}(\%)=100 \sqrt{\frac{\sum\left[\left(q_{\mathrm{e}}-q_{\mathrm{e}, \mathrm{cat}}\right) / q_{\mathrm{e}}\right]^{2}}{N-1}}
$$

where $N$ is the number of data, $q_{\mathrm{e}}\left(\mathrm{mg} \mathrm{g}^{-1}\right)$ is the experimental value and $q_{\mathrm{e} \text {,cat }}\left(\mathrm{mg} \mathrm{g}^{-1}\right)$ is the calculated value by the isotherm equations.

The isotherm parameters calculated from plots of these isotherm equations are given in Table 1 . The Langmuir isotherm model fitted best when the $R^{2}$ values were compared. The value of $Q_{\mathrm{L}}$ was almost equal to the experimental equilibrium adsorption capacity (Fig. 10). The correlation coefficients of the Langmuir isotherm were in the range of 0.9961-0.9992. Moreover, the $\Delta q_{\mathrm{e}}(\%)$ values calculated by the Langmuir isotherm were lowest and narrowest distributed (4.83-9.77\%), which also showed that the adsorption process followed the Langmuir isotherm very well. This indicated that adsorption took place at specific homogenous sites within the adsorbent and that the adsorbed RB molecules were not vertically oriented or strong competition did not exist from the solvent. ${ }^{40}$ It was found that the Freundlich isotherm equation also described the experimental data well with moderate coefficients (0.90840.9824 ) at various temperatures, but with relatively high $\Delta q_{\mathrm{e}}$ (10.46-17.54\%) values. Application of the Freundlich model confirmed that RB adsorption capacity by the MHCMs increased with the temperature, because the value of $K_{\mathrm{F}}$ increased with the temperature. It was observed that the D-R isotherm $\left(0.84<R^{2}<0.94\right)$ did not adequately fit the experimental values. The low coefficients indicated that the removal of RB could not be described by the $\mathrm{D}-\mathrm{R}$ isotherm. The high and

\begin{tabular}{|c|c|c|c|c|c|c|c|c|c|c|c|c|}
\hline $\begin{array}{l}T \\
(\mathrm{~K})\end{array}$ & $\begin{array}{l}Q_{\mathrm{L}} \\
\left(\mathrm{mg} \mathrm{g}^{-1}\right)\end{array}$ & $\begin{array}{l}K_{\mathrm{L}} \\
\left(\mathrm{L} \mathrm{mg}^{-1}\right)\end{array}$ & $R^{2}$ & $\begin{array}{l}\Delta q_{\mathrm{e}} \\
(\%)\end{array}$ & $\begin{array}{l}K_{\mathrm{F}} \\
\left(\mathrm{L} \mathrm{mg}^{-1}\right)\end{array}$ & $n$ & $R^{2}$ & $\begin{array}{l}\Delta q_{\mathrm{e}} \\
(\%)\end{array}$ & $\begin{array}{l}Q_{\mathrm{D}} \\
\left(\mathrm{mg} \mathrm{g}^{-1}\right)\end{array}$ & $\begin{array}{l}\beta \\
\left(\mathrm{mg}^{2} \mathrm{~kJ}^{-2}\right)\end{array}$ & $R^{2}$ & $\begin{array}{l}\Delta q_{\mathrm{e}} \\
(\%)\end{array}$ \\
\hline 288.15 & 212.7 & 0.2999 & 0.9974 & 9.77 & 10.547 & 1.479 & 0.9287 & 10.46 & 196.4 & 87.42 & 0.9152 & 30.95 \\
\hline 298.15 & 277.8 & 0.2081 & 0.9992 & 4.83 & 47.12 & 1.684 & 0.9084 & 13.50 & 218.4 & 1.081 & 0.9404 & 12.95 \\
\hline 303.15 & 312.5 & 0.5000 & 0.9987 & 9.06 & 85.56 & 1.801 & 0.9172 & 17.54 & 248.1 & 0.2022 & 0.8857 & 19.23 \\
\hline
\end{tabular}
wide distributed $\Delta q_{\mathrm{e}}$ values also showed the removal process did not follow the $\mathrm{D}-\mathrm{R}$ isotherm.

Table 1 Isotherms parameters of RB adsorption by MHCMs at various temperatures 
Table 2 Thermodynamic parameters of RB removal by MHCMs

\begin{tabular}{lllll}
\hline$T$ & \multicolumn{1}{l}{$\begin{array}{l}K_{\mathrm{a}} \\
(\mathrm{K})\end{array}$} & $\begin{array}{l}\Delta G \\
\left(\mathrm{~kJ} \mathrm{~mol}^{-1}\right)\end{array}$ & $\begin{array}{l}\Delta H \\
\left(\mathrm{~kJ} \mathrm{~mol}^{-1}\right)\end{array}$ & $\begin{array}{l}\Delta S \\
\left(\mathrm{~J}\left(\mathrm{~mol}^{-1} \mathrm{~K}^{-1}\right)\right)\end{array}$ \\
\hline 288.15 & 79.69 & -10.49 & 28.35 & 134.35 \\
298.15 & 103.86 & -11.51 & & \\
303.15 & 134.83 & -12.36 & & \\
313.15 & 202.82 & -13.83 & & \\
& & & & \\
\hline
\end{tabular}

\subsection{Thermodynamic parameters}

The thermodynamic equilibrium parameters, such as free energy change $(\Delta G)$, enthalpy change $(\Delta H)$ and entropy change $(\Delta S)$, can be determined by the following equations:

$$
\begin{aligned}
& \Delta G=-R T \ln K_{\mathrm{a}} \\
& \ln K_{\mathrm{a}}=\frac{\Delta S}{R}-\frac{\Delta H}{R T}
\end{aligned}
$$

The plot of $\ln K_{\mathrm{a}}$ as a function of $1 / T$ yields a straight line from which $\Delta H$ and $\Delta S$ were calculated from the slope and intercept, respectively. $T$ is the absolute temperature (in Kelvin); $R$ is the universal gas constant $\left(8.314 \mathrm{~J} \mathrm{~mol}^{-1} \mathrm{~K}^{-1}\right)$. The constant $K_{\mathrm{a}}$ was determined by plotting $\ln \left(q_{\mathrm{e}} / C_{\mathrm{e}}\right)$ versus $q_{\mathrm{e}}$ and extrapolating zero $q_{\mathrm{e}}{ }^{39}$ The results are given in Table 2 .

The $\Delta G$ of the adsorption process was negative. This indicated that the adsorption was a spontaneous process. ${ }^{8}$ The absolute value of $\Delta G$ increased as the temperature increased, suggesting that higher temperature was favourable for RB removal. The positive value of $\Delta H\left(28.35 \mathrm{~kJ} \mathrm{~mol}^{-1}\right)$ showed that the RB removal process by MHCMs was endothermic and was favoured at higher temperature. ${ }^{36}$ The $\Delta S$ in the adsorption process was $134.35 \mathrm{~J}\left(\mathrm{~mol}^{-1} \mathrm{~K}^{-1}\right)$. The positive entropy change $(\Delta S)$ value for adsorption corresponded to an increase in the degree of randomness of the adsorbed species. ${ }^{38}$

\subsection{Adsorption kinetics}

Information on the kinetics of pollutant uptake is required for an insight into the adsorption mechanism and for selecting the optimum operating conditions. According to Fig. 11, a higher temperature led to a faster rate and all the curves finally reached equilibrium in $80 \mathrm{~min}$. The adsorption kinetics of uptake of RB onto MHCMs was studied by fitting the pseudo-first-equation and the pseudo-second-order equation. The pseudo-first-order rate model is described as: ${ }^{33}$

$$
\ln \left(q_{\mathrm{e}}-q_{\mathrm{t}}\right)=\ln q_{\mathrm{e}}-k_{1} t
$$

where $q_{\mathrm{e}}$ is the amount of solute adsorbed at equilibrium per unit weight of adsorbent $\left(\mathrm{mg} \mathrm{g}^{-1}\right), q_{\mathrm{t}}$ is the amount of solute adsorbed at any time $\left(\mathrm{mg} \mathrm{g}^{-1}\right)$ and $k_{1}$ is the adsorption constant.

The pseudo-second-order equation can be represented as: ${ }^{34}$

$$
\frac{t}{q_{t}}=\frac{1}{k_{2} q_{\mathrm{e}}^{2}}+\frac{t}{q_{\mathrm{e}}}
$$

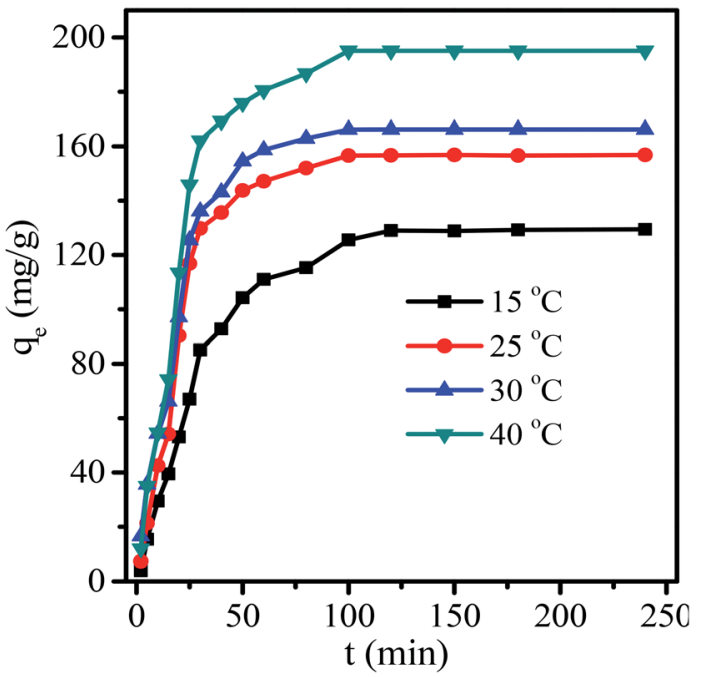

Fig. 11 Kinetic curves for RB removal by MHCMs (RB concentration $100 \mathrm{mg} \mathrm{L}^{-1}$, dosage of MHCMs $0.6 \mathrm{~g} \mathrm{~L}^{-1}, \mathrm{pH}=7$ ).

where $k_{2}\left(\mathrm{~g} \mathrm{mg}^{-1} \mathrm{~min}^{-1}\right)$ is the second-order rate constant and $q_{t}$ is the amount adsorbed at time $t$. The pseudo-first-order kinetic plots and pseudo-second-order kinetic plots are presented in Fig. S4 and S5 in the ESI. $\dagger$ The values of $k_{1}, k_{2}$ and the corresponding correlation coefficients $\left(R^{2}\right)$ are summarized in Table 3.

The $R^{2}$ values $\left(0.8523<R^{2}<0.9496\right)$ showed that the pseudofirst-order kinetics did not adequately fit the experimental values. The pseudo-second-order kinetic model described all the adsorption processes very well according to the correlation coefficients, of which the correlation coefficients were above 0.9853. Moreover, the equilibrium $q_{\mathrm{e}}$ obtained from this model was closely in line with the experimental value. The well-fitting of the pseudo-second-order equation suggested that the adsorption process was interaction controlled. ${ }^{40,41}$

The insight of activation energy may give an idea about the type of adsorption. The activation energy of RB absorption by MHCMs was determined using the Arrhenius equation: ${ }^{41-43}$

$$
\ln k=\frac{-E_{\mathrm{a}}}{R T}+\ln A
$$

where $E_{\mathrm{a}}$ is activation energy, $R$ is the gas constant $(8.314 \mathrm{~J}$ $\left.\left(\mathrm{mol}^{-1} \mathrm{~K}^{-1}\right)\right), T$ is the temperature in Kelvin, $k$ is the adsorption rate constant and $A$ is the frequency factor. The value of $E_{\mathrm{a}}$ can be determined from the slope of lnk versus $1 / T$ plot (the plot of lnk vs. $1 / T$ is shown in Fig. S6 in the ESI†).

The adsorption rate constants according to the pseudosecond-order kinetic model at various temperatures were used to calculate the activation energy value. Generally, the activation energy in a physical adsorption is below $4.2 \mathrm{~kJ} \mathrm{~mol}^{-1}$ and chemical adsorption involves forces much stronger than that of physical adsorption..$^{42}$ The activation energy $\left(E_{\mathrm{a}}\right)$ of the adsorption process was $5.04 \mathrm{~kJ} \mathrm{~mol}^{-1}$, which indicated the dominant physical adsorption mechanism accompanied by the existence of chemisorption. 
Table 3 Kinetic parameters for RB adsorption by MHCMs

\begin{tabular}{|c|c|c|c|c|c|c|}
\hline$T \mathrm{~K}$ & \multicolumn{3}{|c|}{ Pseudo-first-order equation } & \multicolumn{3}{|c|}{ Pseudo-second-order equation } \\
\hline 298.15 & 0.0402 & 111.90 & 0.9034 & 0.377 & 161.29 & 0.9957 \\
\hline 303.15 & 0.0698 & 270.20 & 0.9496 & 0.386 & 175.44 & 0.9928 \\
\hline 313.15 & 0.0786 & 468.15 & 0.9145 & 0.418 & 200.00 & 0.9939 \\
\hline
\end{tabular}

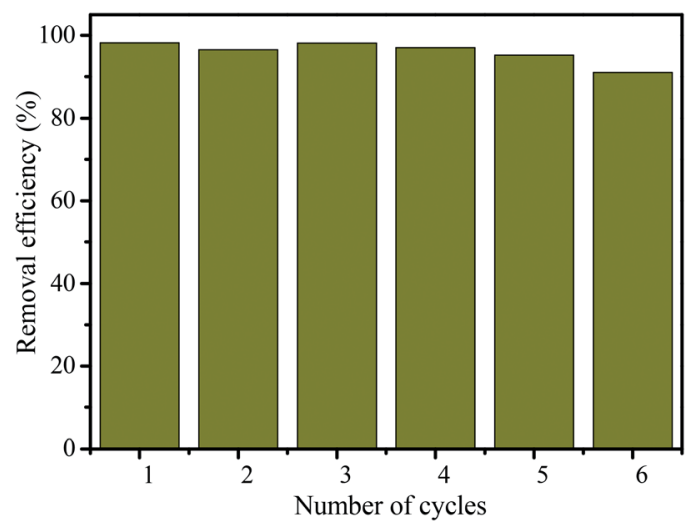

Fig. 12 Recycling of MHCMs for the removal of RB from actual solutions (RB concentration $100 \mathrm{mg} \mathrm{L}^{-1}$, dosage of MHCMs $2.0 \mathrm{~g} \mathrm{~L}^{-1}$, temperature $25^{\circ} \mathrm{C}$ and contact time $60 \mathrm{~min}$ ).

\subsection{Reusability of MHCMs for RB removal}

The regeneration and reusability of adsorbents are very important in their industrial applicability. In order to study the reusability of the MHCMs as an adsorbent, recycling experiments were conducted with each cycle of $60 \mathrm{~min}$ contact time using $2 \mathrm{~g} \mathrm{~L}^{-1}$ MHCMs dosage. After each cycle, the MHCMs were separated by a magnet and regenerated by treatment with $1.0 \mathrm{~mol} \mathrm{~L}^{-1}$ sodium hydroxide and heated at $400{ }^{\circ} \mathrm{C}$ for $1.0 \mathrm{~h}$ in nitrogen. As shown in Fig. 12, after six consecutive cycles, the removal efficiency of RB still remained over $90 \%$. This demonstrated the high regeneration capability of MHCMs and their good reusability for $\mathrm{RB}$ removal. The results revealed that the MHCMs were a favourable reusable adsorbent for the removal of RB from aqueous solutions.

\section{Conclusions}

Porous magnetic hollow carbon microspheres (MHCMs) were fabricated by a combination of microwave-assistant polycondensation and surfactant-free emulsion polymerization. The MHCMs possessed uniform morphologies, high surface areas, large pore volume and magnetic responsiveness. The BET surface area of the MHMCs was as high as $680 \mathrm{~m}^{2} \mathrm{~g}^{-1}$ with a total pore volume of $0.61 \mathrm{~cm}^{3} \mathrm{~g}^{-1}$. The adsorption of RB by MHCMs was studied in aqueous solution. With a dosage of $2.0 \mathrm{~g}$ $\mathrm{L}^{-1}$, the removal efficiency of $\mathrm{RB}\left(100 \mathrm{mg} \mathrm{L}^{-1}\right)$ reached $99.5 \%$. The adsorption capacity of the MHCMs reached as high as 300 $\mathrm{mg} \mathrm{g}^{-1}$ when the dosage was $0.1 \mathrm{~g} \mathrm{~L}^{-1}$. The adsorption process followed the Langmuir isotherm very well with very high correlation coefficient values (0.9961-0.9992) and low normalized standard deviation $\Delta q_{\mathrm{e}}$ values (4.83-9.77\%). The adsorption kinetics fitted well with a pseudo-second-order kinetics model. The activation energy $\left(E_{\mathrm{a}}\right)$ of the adsorption process was $5.04 \mathrm{~kJ} \mathrm{~mol}^{-1}$. After six consecutive cycles, the removal efficiency of RB still remained over $90 \%$. These results indicated the promising application of MHCMs as a high performance reusable adsorbent.

\section{Acknowledgements}

We gratefully acknowledge the financial support of the National Natural Science Foundation of China (Grant No. 51503040 and 31401609), the Talent Fund of Fuzhou University (Grant No. XRC-1462), and the Natural Science Foundation of Fujian province (Grant No. 2016J01733).

\section{Notes and references}

1 P. Niu and J. Hao, Colloids Surf., A, 2014, 443, 501-507.

2 G. Das, T. Skorjanc, T. Prakasam, S. Nuryyeva, J. C. Olsen and A. Trabolsi, RSC Adv., 2017, 7, 3594-3598.

3 E. Emilia Rios-Del Toro, L. B. Celis, F. J. Cervantes and J. Rene Rangel-Mendez, J. Hazard. Mater., 2013, 260, 967974.

4 C. Yang, S. Wu, J. Cheng and Y. Chen, J. Alloys Compd., 2016, 687, 804-812.

5 C. Cai, H. Zhang, X. Zhong and L. W. Hou, Water Res., 2014, 66, 473-485.

6 M. Mohammadi, A. J. Hassani, A. R. Mohamed and G. D. Najafpour, J. Chem. Eng. Data, 2010, 55, 5777-5785.

7 H. Liu, X. Ren and L. Chen, J. Ind. Eng. Chem., 2016, 34, 278285.

8 L. You, F. Lu, L. Song, Y. Yin and Q. Zhang, RSC Adv., 2015, 5, 64711-64723.

9 S. K. Giri, N. N. Das and G. C. Pradhan, Colloids Surf., A, 2011, 389, 43-49.

10 J. Ma, D. Huang, W. Zhang, J. Zou, Y. Kong, J. Zhu and S. Komarneni, Chemosphere, 2016, 162, 269-276.

11 S. Kaur, V. Bhalla and M. Kumar, ACS Appl. Mater. Interfaces, 2015, 7, 16617-16624.

12 I. Zawierucha, C. Kozlowski and G. Malina, Environ. Sci.: Processes Impacts, 2016, 18, 429-444.

13 Y. Wu, M. Zhang, H. Zhao, S. Yang and A. Arkin, RSC Adv., 2014, 4, 61256-61267. 
14 Y. Y. Qu, X. Y. Cao, Q. Ma, S. G. Shi, L. Tan, X. L. Li, H. Zhou, X. W. Zhang and J. T. Zhou, J. Hazard. Mater., 2012, 223-224, 31-38.

15 B. V. Mohite, V. Bhavna and S. V. Patil, J. Biomater. Sci., Polym. Ed., 2014, 25, 2053-2065.

16 J. P. Jadhav, G. K. Parshetti, S. D. Kalme and S. P. Govindwar, Chemosphere, 2007, 68, 394-400.

17 T. Chen, B. Y. Gao and Q. Y. Yue, Colloids Surf., A, 2010, 355, 121-129.

18 R. Sanghi and P. Verma, Color. Technol., 2013, 129, 85-108.

19 P. Patricio, M. P. Cláudia, R. L. T. Elaine, G. M. Sandra, A. R. Maria, C. M. Rosana and D. Nelson, Appl. Catal., B, 2003, 42, 131-144.

20 L. You, Y. Zhang, S. Xu, J. Guo and C. Wang, ACS Appl. Mater. Interfaces, 2014, 6, 15179-15187.

21 M. Dai, L. Xia, S. Song, C. Peng and A. Lopez-Valdivieso, J. Hazard. Mater., 2016, 281, 312-317.

22 J. Feng, J. Gong, X. Wen, N. Tian, X. Chen, E. Mijowska and T. Tang, RSC Adv., 2014, 4, 26817-26823.

23 L. D. Virla, V. Montes, J. Wu, S. F. Ketep and J. M. Hill, Microporous Mesoporous Mater., 2016, 234, 239-247.

24 Z. Wang, F. Zhang, Y. Lu, B. Zhai, S. Zhai, Z. Xiao, Q. An, C. Yu and S. Gao, Mater. Res. Bull., 2016, 83, 590-596.

25 C. Liang, Z. Li and S. Dai, Angew. Chem., Int. Ed., 2008, 47, 3696-3717.

26 P. Adelhelm, Y. S. Hu, L. Chuenchom, M. Antonietti, B. M. Smarsly and J. Maier, Adv. Mater., 2007, 19, 4012-4017.

27 S. Zeng, S. Duan, R. Tang, L. Li, C. Liu and D. Sun, Chem. Eng. J., 2014, 258, 218-228.

28 S. Xu, W. Ma, L. You, J. Li, J. Guo, J. J. Hu and C. Wang, Langmuir, 2010, 28, 3271-3278.
29 L. You, S. Xu, W. Ma, D. Li, Y. Zhang, J. Guo, J. J. Hu and C. Wang, Langmuir, 2012, 28, 10565-10572.

30 X. Y. Dai, X. Zhang, Y. F. Meng and P. K. Shen, New Res. Carbon Mater., 2011, 26, 389-395.

31 R. Y. Hong, B. Feng, G. Liu, S. Wang, H. Z. Li, J. M. Ding, Y. Zheng and D. G. Wei, J. Alloys Compd., 2009, 476, 612-618.

32 C. F. Martín, M. G. Plaza, S. García, J. J. Pis, F. Rubiera and C. Pevida, Fuel, 2011, 90, 2064-2072.

33 S. Chaudhary, P. Sharma, Renu and R. Kumar, RSC Adv., 2016, 6, 62797-62809.

34 D. Li, D. Chen, Y. Yao, J. Lin, F. Gong, L. Wang, L. Luo, Z. Huang and L. Zhang, Chem. Eng. J., 2016, 288, 806-812.

35 L. Ding, B. Zou, W. Gao, Q. Liu, Z. Wang, Y. Guo, X. Wang and Y. Liu, Colloids Surf., A, 2014, 446, 1-7.

36 G. Zhou, C. Liu, Y. Tang, S. Luo, Z. Zeng, Y. Liu, R. Xu and L. Chu, Chem. Eng. J., 2015, 280, 275-282.

37 F. Zhao, E. Repo, D. Yin and M. E. Sillanpaa, J. Colloid Interface Sci., 2013, 409, 174-182.

38 M. Mohammadi, A. J. Hassani, A. R. Mohamed and G. D. Najafpour, J. Chem. Eng. Data, 2010, 55, 5777-5785.

39 A. S. Ozcan, B. Erdem and A. Ozcan, Colloids Surf., A, 2005, 266, 73-81.

40 Q. Li, Q. Yue, H. Sun, Y. Su and B. Gao, J. Environ. Manage., 2010, 91, 1601-1611.

41 L. You, L. Song, F. Lu and Q. Zhang, Polym. Eng. Sci., 2016, 56, 1213-1220.

42 H. Ucun, Y. K. Bayhan and Y. Kaya, J. Hazard. Mater., 2008, 153, 52-59.

43 E. Oguz, Colloids Surf., A, 2005, 252, 121-128. 